\title{
ARTICLES
}

\author{
Nadezhda Kotova' ${ }^{1}$, Peter Stadler ${ }^{2}$, Tomasz Goslar ${ }^{3}$
}

\section{BARK PITCH IN THE EARLY NEOLITHIC OF CENTRAL EUROPE}

\begin{abstract}
Kotova N., Stadler P. and Goslar T. 2021. Bark pitch in the Early Neolithic of Central Europe. Sprawozdania Archeologiczne 73/2, 9-23.

The Linear Pottery people in 5670-500o BC at the Brunn sites in Austria produced birch and beech bark pitches. Big globular vessels and closed high bowls could have been containers for the production and storage of this substance. Miniature vessels with a handle for hanging had contained small portions. Bark pitch as an adhesive for the repair of pottery and in the construction of big idols is also testified, as is the application of this material in decoration of vessels and idols, where bark pitch was a matrix for inlaying with grains or stones and creation of a contrasting black colour in linear ornamentation. Radiocarbon dating of bark pitch now is one of the most reliable materials for age determination of the Neolithic objects.
\end{abstract}

Keywords: Linear Pottery culture, Central Europe, using of bark pitch in the Neolithic, radiocarbon dates Received: 12.03.2021; Revised: 08.05.2021; Accepted: 16.10.2021

1 Institute of Archaeology Ukrainian Academy of Sciences, 12 Prospekt Heroyiv Stalinhradu, Kyiv 04210, Ukraine; nadja.kotova@hotmail.com; ORCID: 0ooo-0oo2-8197-7782

2 Institut für Urgeschichte und Historische Archäologie, Universität Wien, Franz-Klein-Gasse 1, A-119o Wien, Austria; Peter.Stadler@univie.ac.at; ORCID: 0ooo-0003-4000-3778

3 Poznań Radiocarbon Laboratory, Poznań Park of Science and Technology, Rubież 46, 61-612 Poznań, Poland; tomasz.goslar@radiocarbon.pl; ORCID: oooo-0oo2-1346-3122 


\section{INTRODUCTION}

Bark pitch was widely used in the Palaeolithic, Mesolithic and Neolithic periods. It can be considered as a substance that in prehistoric times was a real "multifunctional" one: it is known to have been frequently used for a variety of purposes, e.g., as coating of pottery, as an adhesive for ancient repair work, and in the construction of weapons (e.g. fixing flint arrowheads to their handles or shafts), and even as a gift offered in ancient rites (Sauter

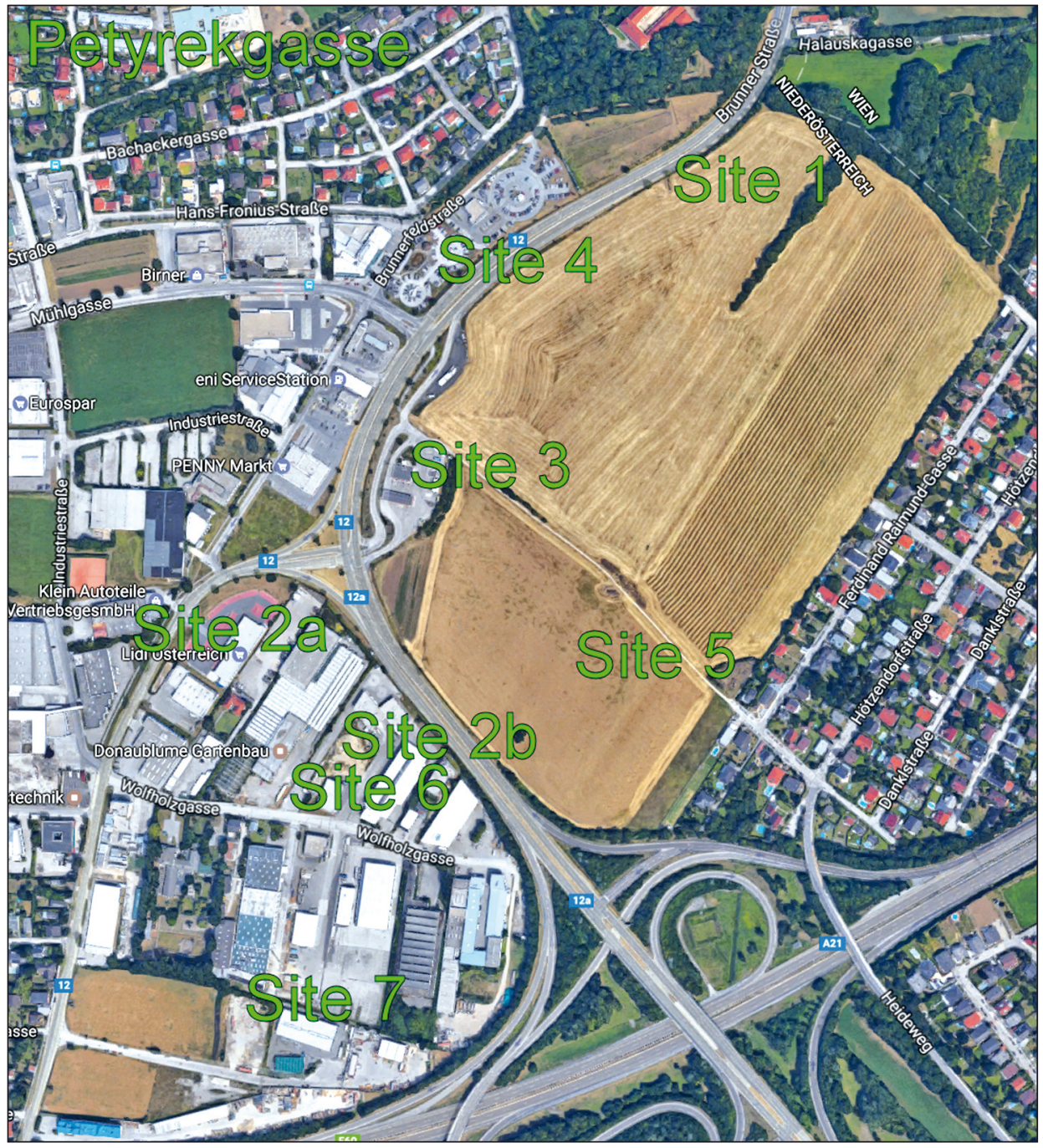

Fig. 1. Location of the Brunn sites 
et al. 2019). Data have been collected (Hansen 2019) about the use of pitch and bitumen for the decoration of the Prehistoric idols in the Near East (as imitation of hair) and on European Neolithic pots (Geometric patterns were formed with straw pieces inserted into bitumen in the Tisza culture, ornamental patterns in birch pitch coatings to Cortaillod vessels). Small lumps of this organic material are found on archaeological sites with tooth imprints, indicating that they were chewed. Ethnographic evidence suggests that birch pitch was used as a natural antiseptic for preventing and treating dental ailments and other medical conditions, because of the presence of botulin, which is one of the main constituents of birch pitch (Jensen et al. 2019).

\section{MATERIALS}

A collection of ceramics with bark pitch has been studied at the sites of the Linear Pottery culture in Lower Austria (Sauter et al. 2019). In 1989-2005 P. Stadler excavated six sites of the Linear Pottery culture (Brunn 1-6, see Fig. 1) near the village Brunn am Gebirge, $1 \mathrm{~km}$ from the southern outskirts of Vienna. These sites demonstrate a development of the local Linear Pottery culture from the Formative phase (Brunn 2 site, 5660-5350 calBC) till the Note phase (the Brunn 6 site, 5050 calBC). Three sites (Brunn 1, 2 and 3) contain sherds with bark pitch. These sherds belong to seven vessels from the Brunn 1 site (the Flomborn phase), two vessels from the Brunn 3 site (the Milanovce phase); six vessels and an idol from Brunn 2 (the Formative phase). Only in one feature we have found three vessels with black spots (Feature 2111 in House 67 at Brunn 1, Fig. 2: 1-3) and in two other features - two vessels (Feature 2107 in House 68 and Feature 88 in House 7 at Brunn 2). Other vessels have been found in different houses and features.

\section{RESULTS}

Chemical analysis was conducted for eight samples of vessels (Fig. 2: 5,$6 ; 3 ; 4 ; 5: 2$; Puchinger et al. 2019) and for an idol (Fig. 6; Sauter et al. 2019). Most of these vessels have spots of pitch made from the bark of the birch (Betula pendula) and Sample 7 (Fig. 4: 3) was prepared from the European beech (Fagus sylvatica).

\section{DISCUSSION}

The location of the bark pitch spots serves as a basis for reconstruction the usage of this material. We can divide the examined ceramics with bark pitch into three groups: pottery with amorphous spots and ceramics with bark pitch as a part of the decoration and using of this material as adhesive. 

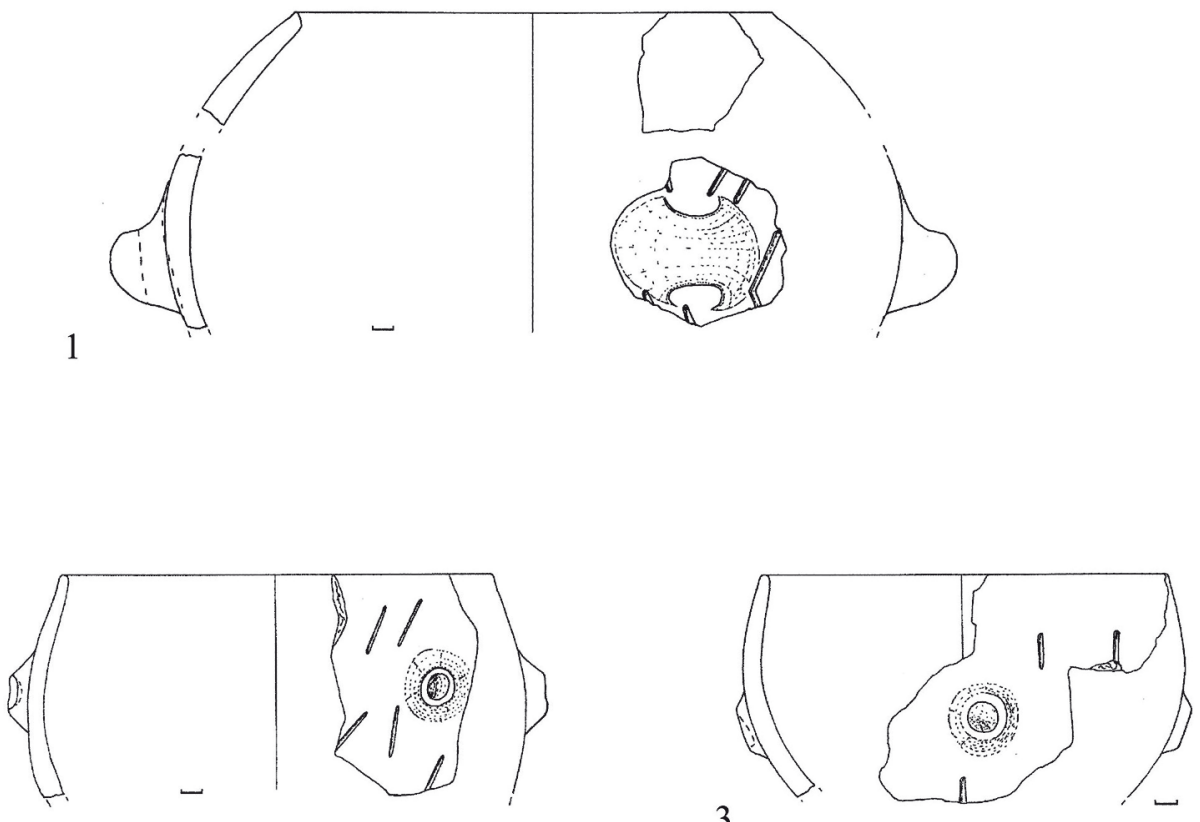

2

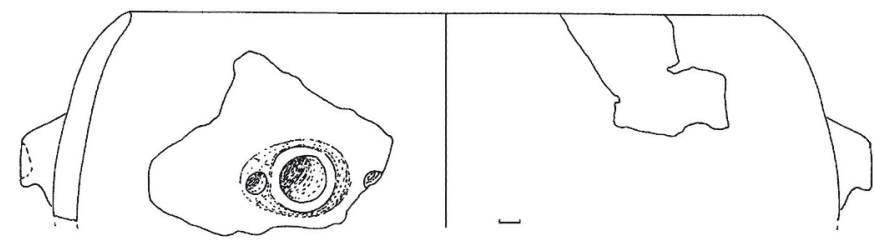

4
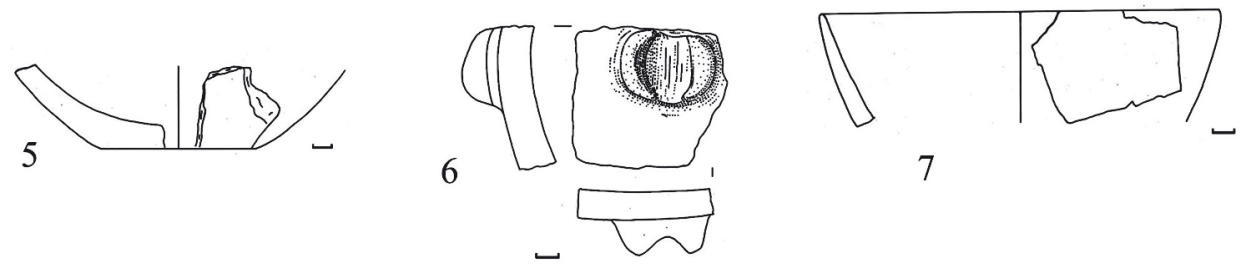

Fig. 2. Pottery with bark pitch of the Brunn 1 site:

1-3 - Feature 2111; 4 - Feature 2114; 5 - Feature 88; 6 - Feature 123; 7 - Feature 202

(Drawings: Nadezhda Kotova) 
The first group includes most of the vessels that exhibit small spots of bark pitch on their surfaces. Analysis of the types of these vessels has shown one big globular vessel (Fig. 2: 1), three closed high bowls (Fig. 2: 2, 3, 4), one open high bowl (Fig. 3: 4), an amphora (Fig. 5: 1), two miniature vessels with handles (Fig. 4), two bases from not big vessels (Fig. 2: $5 ; 3: 8$ ) and two fragment of walls (Fig. 2: 6;3:7). The most interesting set of vessels with bark pitch was in Feature 2111: a big globular vessel and two middle size closed high
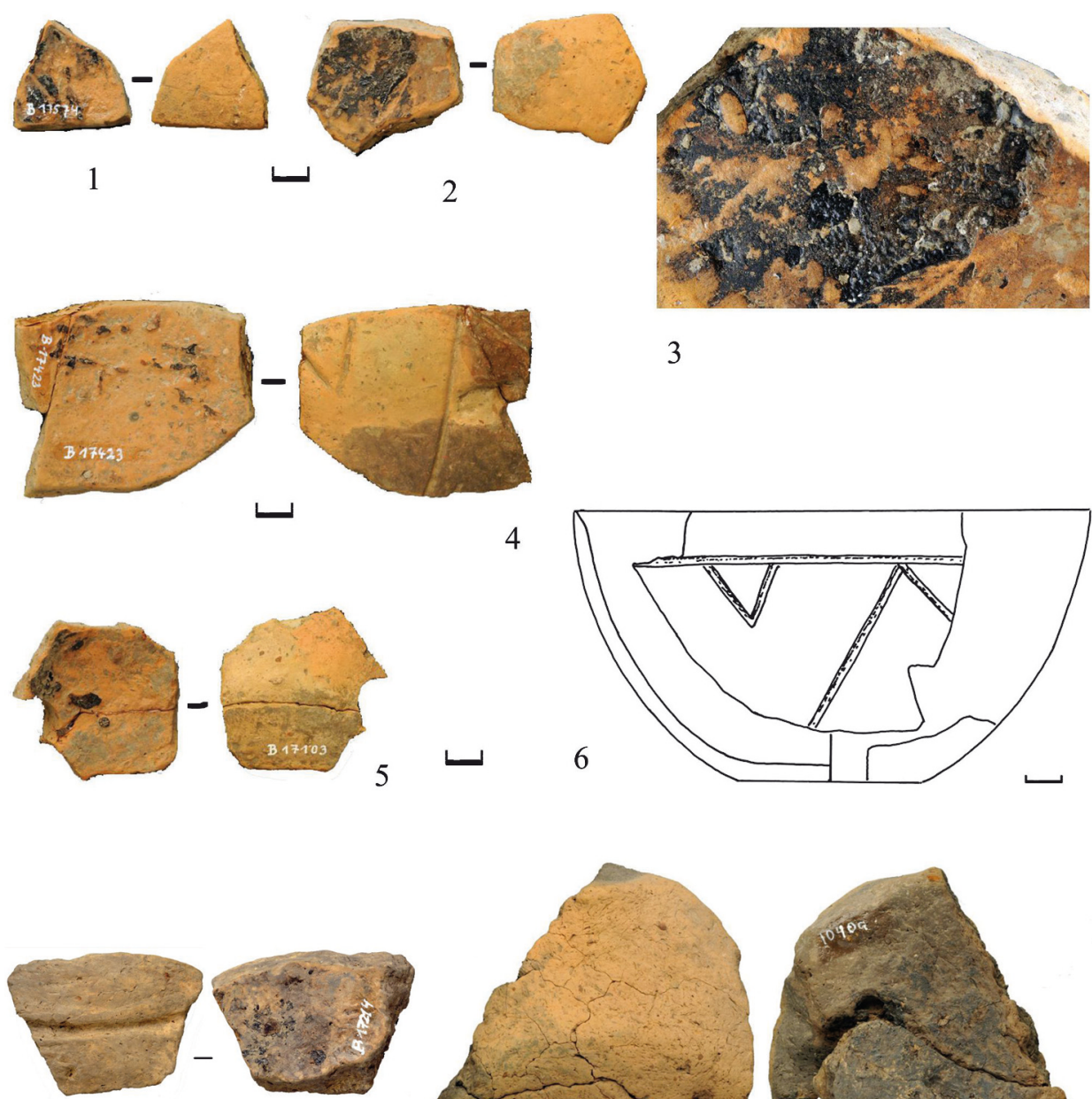

7
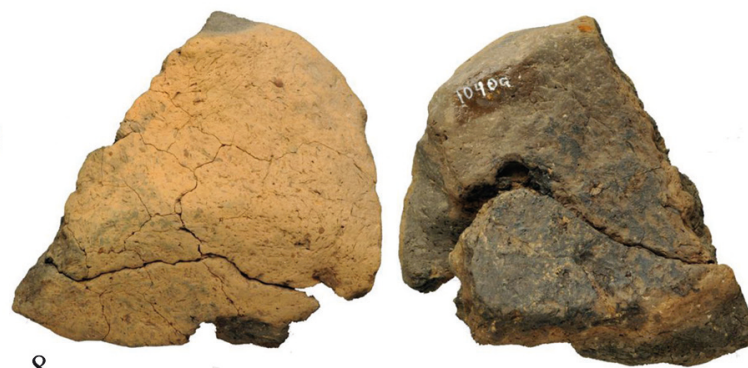

8

Fig. 3. Pottery with bark pitch: 1-7 - Brunn 1 Feature 2107; 8 - Brunn 2 Feature 101

(Photos: Alice Schumacher; drawings: Nadezhda Kotova) 


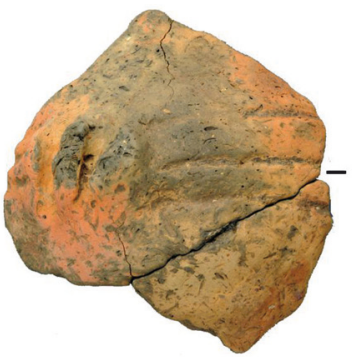

1

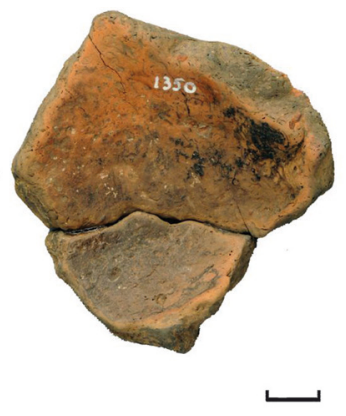

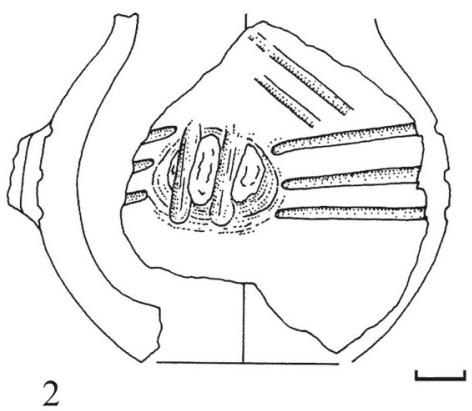

2

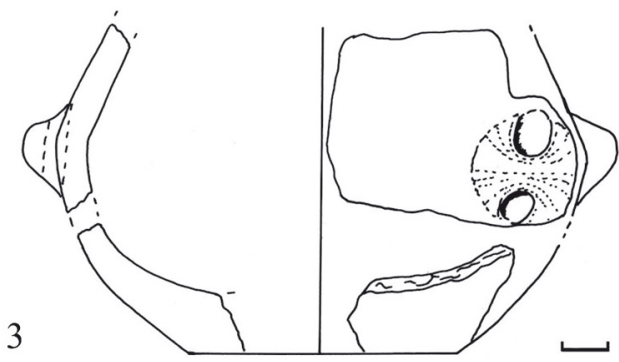

Fig. 4. Pottery with bark pitch: 1, 2 - Brunn 2 site, Feature 144; 3 - Brunn 3, Feature 1717

(Photos: Alice Schumacher; drawings: Nadezhda Kotova)

bowls (Fig. 2: 1-3). Only the amphora and a fragment with knob from a big vessel have black spots on the outer surfaces (Fig. 2: 6; 5:1). The black spots on the other vessels are located on the inside surface of walls and bases.

\section{Vessels for production and storage of pitch}

Two miniature pots with spots of bark pitch inside had exceedingly small handles that could have been used only for hanging (Fig. 4). These miniature vessels could have served for storage.

Big vessels (the globular vessel and high bowls) could have been containers used in the process of production or storage of bark pitch. The three oldest methods of bark production have been reconstructed and two of them needed containers (Kozowyk et al. 2017). It is possible that the inhabitants of House 67 at Brunn 1, where three big closed vessels were found (Fig. 2: 1-3), produced and stored bark pitch. 


\section{Possible using of pitch together with a bung for closure of an amphora}

Two big vessels with bark pitch on the outer surfaces, among which are the amphora (Fig. 5), could have received these spots accidentally. It is an attractive idea that wine or beer was stored in this amphora and its mouth was closed with a bung together with bark pitch. However, we have no information about the use of alcohol at the Brunn sites, only the impression of barley grain on the idol from the Brunn 2 site (Kotova and Stadler 2019, 381) and carbonized wheat grains in a pit at Brunn 6 (Wiesinger 2019). Excepting numerous amphorae, the Brunn collection includes a small vessel of specific shape, similar to a modern wineglass (Fig. 5: 3).

\section{Bark pitch usage as adhesive}

The possible use of bark pitch as an adhesive is represented by a small low bowl, which has a spot on the break point (Fig. 2: 7). This localization allows the assumption that this material was used for the repair of this small vessel.

Bark pitch was also used as an adhesive in the construction of a big idol from the Brunn 2 site. This idol may have had a height of about $30 \mathrm{~cm}$ (Fig. 6). A vertical hole was situated in the centre of the head and it had traces of bark pitch, which are visible in photographic magnification. It is possible to guess that a small wooden stick connected head and body and that the bark pitch served as a stable fixation.

\section{Usage of bark pitch as a part of decoration}

The big idol from the Brunn 2 site has a linear decoration. Some spots of black birch pitch are preserved in a few places in the lines, which are visible in magnified photographs (Fig. 6), and in the eyes. This suggests an idea about the inlaying of the big round eyes with grains or stones. This possibility was assumed for the round eyes of other LBK idols (Gallay and Hansen 2006). S. Hansen assumes that the birch pitch detected in the incised lines on the hips of this idol could have been used to attach an additional material, e.g. fabric, leather or straw or served as a colour contrast, including the possibility that the statuette from Brunn am Gebirge was wholly or partly covered with birch pitch (Hansen 2019). We think that bark pitch in the lines of decoration could have also been used for the fixation of grains or to create a contrast of black colour for the linear decoration.

Beech bark pitch was preserved also in the lines of decoration on a high bowl from the Brunn 3 site (Fig. 5: 2). We assume that this bowl was inlaid with grains that were put in the line on a black matrix layer of beech bark pitch. The background to this hypothesis is the shape of two lines, which consist of ovals, similar in size to that of grains. 

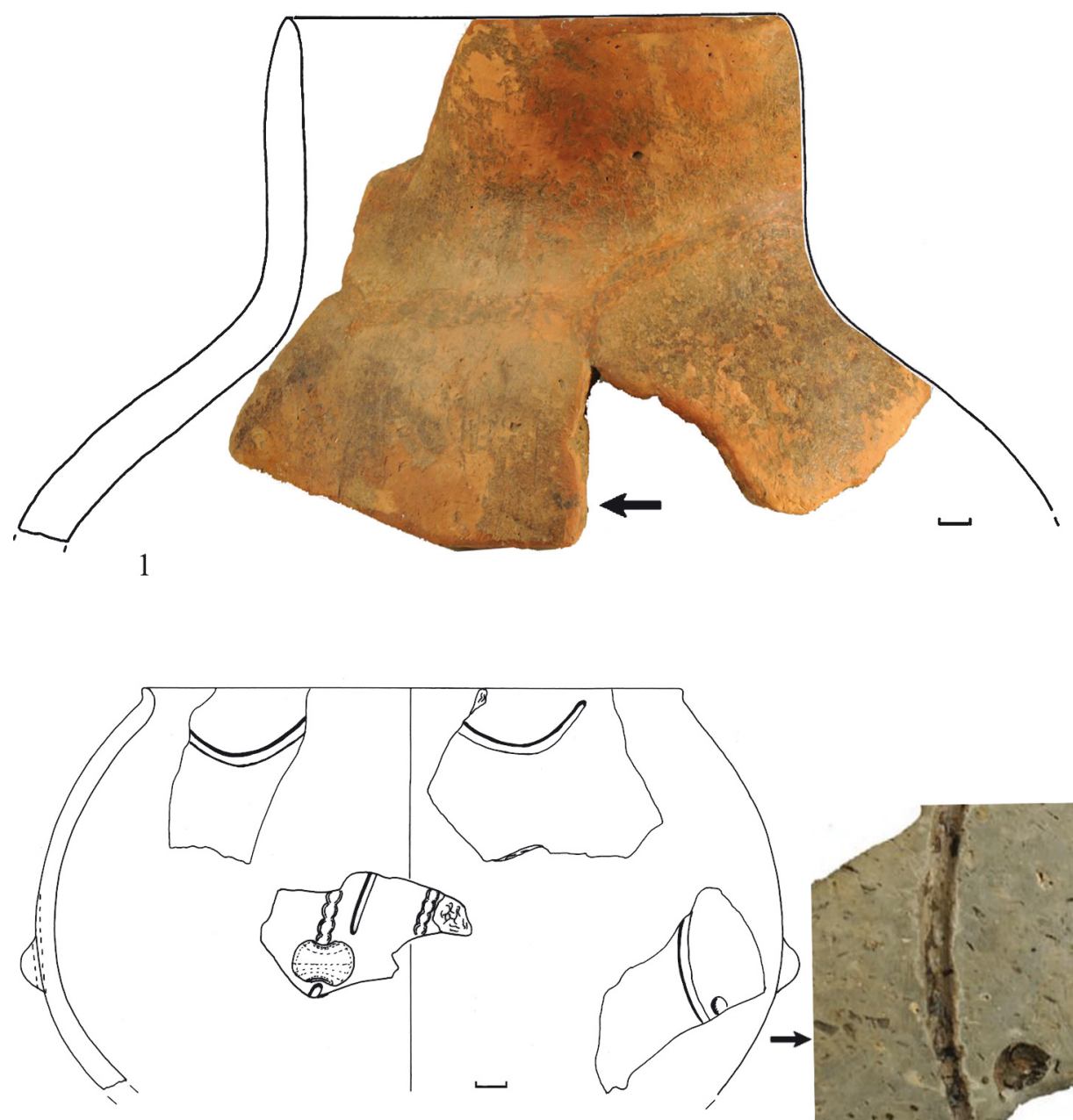

2

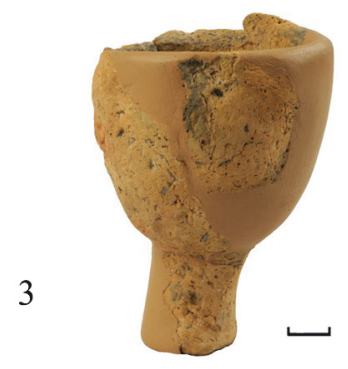

Fig. 5. Pottery with bark pitch: 1 - Brunn 1 Feature I222; 2, 3 - Brunn 3, Feature 1773

(Photos: Alice Schumacher; drawings: Nadezhda Kotova) 

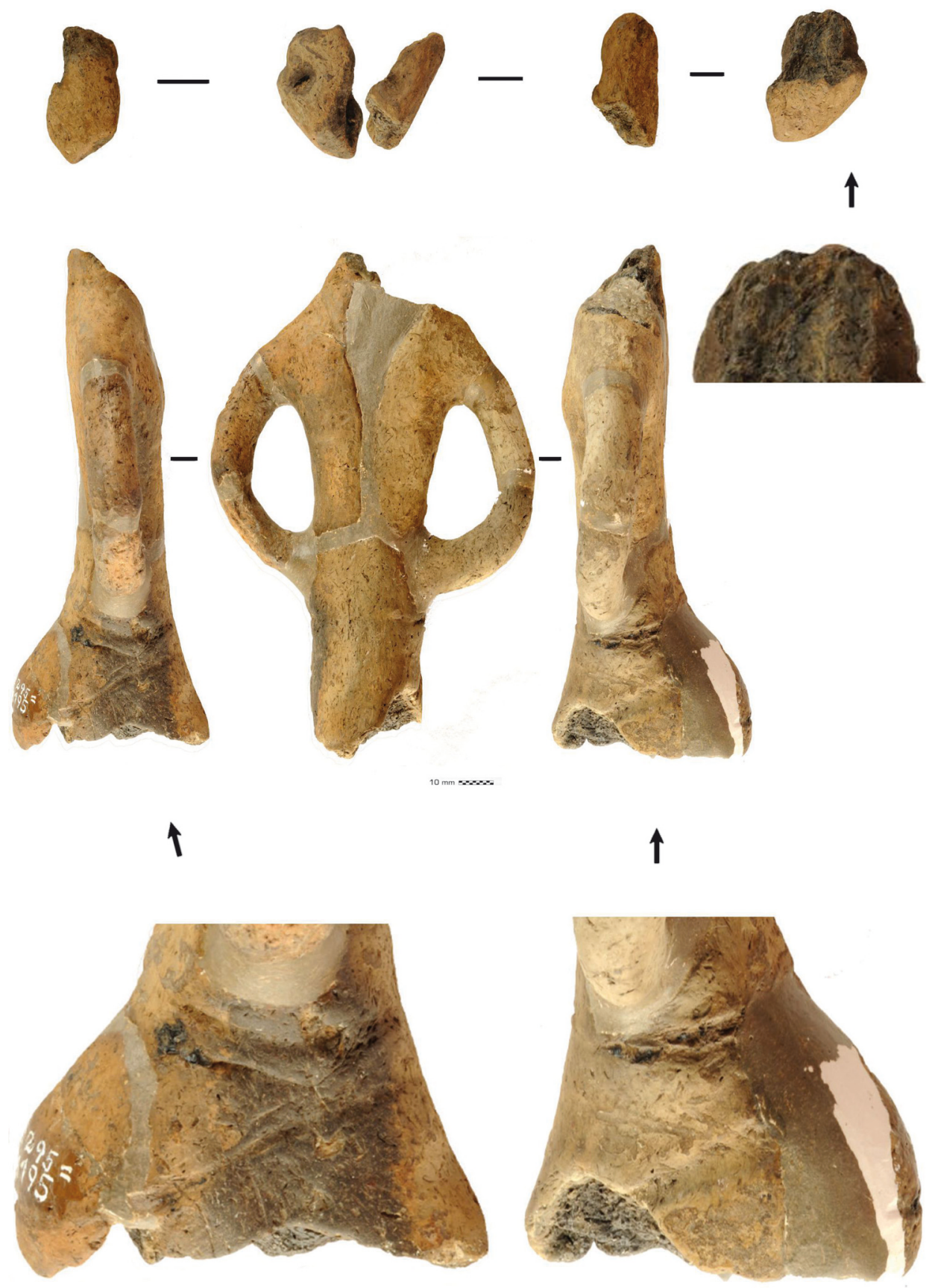

Fig. 6. Idol with bark pitch from Feature 167 of the Brunn 2 site (Photos: Alice Schumacher) 


\section{The use of bark pitch in the study of the Central European Early Neolithic}

Radiocarbon dating of bark pitch is an extremely important variant of using of this material in the study of Linear Pottery culture. The method of radiocarbon dating by AMS now is the most popular among archaeologists for the definition of the age of ancient objects; experts from different laboratories are constantly improving it and receiving better and better results. However, now we have the same problems as fifty year ago, which cannot be decided with the improvement of new AMS apparatus and new methods of carbon cleaning. These objective problems are connected with the old-wood effect, which appear in the dating charcoal or some wood products from archaeological objects, or with the reservoir effect with human bones, the bones of some animals and even of charred residue adhering to pottery, in which sea or river food products were cooked. Hope is often placed in the use of material such as seeds as a reliable sample for radiocarbon dating, but this is only justifiable if they were found in a pot or in a fireplace or in a storage building (as we have found it at Brunn), when we can be sure that they belonged to the main phase of settlement. However, sometimes they are found in a pit without pottery, which could be older or younger than the main site, on which these pits are located.

Some years ago, the method of direct dating of carbon from organic additions in ceramics looked like a way that could be improved in the nearest future. Numerous dates were received, especially for the Russian Neolithic. The results were collected in some articles in Documenta Praehistorica 44, 2017, for example, Lychagina and Vybornov 2017. However, all these dates from different laboratories can be considered as reliable only in the few cases when they are similar to dates for botanical and collagen dates and can be used only together with other dates, if no contradictions arise in the results. For example, numerous and various samples for radiocarbon dating from the Brunn sites (charcoal, animal and human bones, seeds, organic additions in ceramic clay, and bark pitch) allow us to eliminate a series of dates for pottery that are younger by 1000 years or older by 700 years. This fact minimizes the usefulness of making of dates from carbon contained in the pottery fabric at the current level of cleaning carbon from ceramics and separation of organic remains from plants that were added to clay, and the organic remains (carbonised residues of vegetation of land and water origin) from the silt from which the main part of the Eastern European Neolithic pottery was made (Vasileva 2006).

Now a new method of dating of lipids from pottery is beginning to be used and it looks to really be one of the most reliable (Casanova et al. 2020). However, this method is not applicable to mass dating because of the specific process of lipid separation.

All these facts make the dating of bark pitch from prehistoric sites very important. For a long time it has been in use for definition of age of the Neolithic and Eneolithic sites in Fennoscandia, where about $60-70$ prehistoric sites were known by the end of the $20^{\text {th }}$ millennium (Pesonen 1999). Numerous dates in different laboratories were made for samples of bark pitch in this region and related areas of Russia (Tarasov et al. 2017). 


\begin{tabular}{|c|c|c|c|c|c|c|c|c|c|c|c|c|c|c|}
\hline $\mathrm{D} \%$ & $\begin{array}{l}0 \\
\text { i. } \\
\infty\end{array}$ & $\approx$ & $\approx$ & $\ddot{8}$ & $\infty$ & in & $\ddot{\sigma}$ & $\stackrel{n}{0}$ & $\frac{1}{5}$ & $\stackrel{\infty}{i}$ & $\underline{\Xi}$ & $\begin{array}{l}\infty \\
\stackrel{\infty}{\infty}\end{array}$ & $\stackrel{a}{i}$ & $\overrightarrow{8}$ \\
\hline 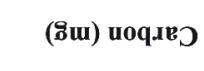 & $\stackrel{\nabla}{m}$ & $\begin{array}{c}1 \\
3 \\
0 \\
0\end{array}$ & 疍 & $\begin{array}{l}c \\
O \\
i \\
i\end{array}$ & গิ & $\infty$ & $\bar{n}$ & $\stackrel{m}{0}$ & 导 & 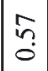 & $\begin{array}{l}0 \\
0 \\
0\end{array}$ & $\stackrel{n}{m}$ & 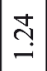 & $\stackrel{\infty}{\infty}$ \\
\hline 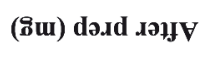 & $\stackrel{\infty}{m}$ & $m$ & $\stackrel{9}{\longrightarrow}$ & $\vec{i}$ & $\stackrel{\infty}{0}$ & m & $\stackrel{0}{-}$ & $\stackrel{\infty}{\infty}$ & $\mathrm{N}$ & $=$ & $\ddot{0}$ & ले & $\cong$ & $\stackrel{+}{i}$ \\
\hline (8̂u) də.dd o.L & $\overrightarrow{0}$ & $\stackrel{m}{=}$ & $\bar{i}$ & $\stackrel{+}{ \pm}$ & $\ddot{m}$ & $\stackrel{0}{2}$ & $n$ & $\vec{m}$ & 广 & $\vec{m}$ & $\because$ & $\begin{array}{l}+ \\
\infty\end{array}$ & t & m \\
\hline 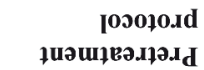 & 워N & $\stackrel{x}{N}$ & ○ & สุ & $\overbrace{0}^{0}$ & $\underset{6}{0}$ & $\underset{\ominus}{\varnothing}$ & $\bigodot_{\ominus}$ & 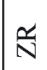 & రొ & రొ & $\stackrel{\dddot{N}}{\mathrm{~N}}$ & $\underset{\bullet}{\mathscr{E}}$ & $\underset{\wp}{0}$ \\
\hline Zวg|вว & $\begin{array}{l}n \\
n \\
n\end{array}$ & $\begin{array}{l}R \\
0 \\
i n \\
i n\end{array}$ & $\mid \begin{array}{c}R \\
2 \\
i n \\
i n\end{array}$ & 早 & & $\frac{0}{m}$ & $\begin{array}{l}8 \\
0 \\
0\end{array}$ & 只 & 8 & 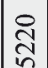 & 号 & 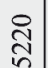 & $\stackrel{n}{\pi}$ & 8 \\
\hline IวЯIE) & 웅 & $\stackrel{2}{\infty}$ & $\frac{1}{5}$ & 온 & 움 & 寽 & 寽 & 只 & 忿 & $\frac{n}{m}$ & ৪্ল & $\frac{m}{m}$ & \& & $\stackrel{\circ}{\sim}$ \\
\hline ยนถิIS & 우 & 8 & o & 8 & 오 & 오 & 8 & 8 & 오 & 오 & 8 & 우 & $n$ & 오 \\
\hline dg & $\begin{array}{l}8 \\
\& \\
0\end{array}$ & $\frac{8}{8}$ & $\mid \begin{array}{c}0 \\
\text { 范 } \\
\end{array}$ & $\mid$ & 音 & $\underset{\infty}{\infty}$ & $\begin{array}{l}8 \\
8 \\
0 \\
0\end{array}$ & $\begin{array}{l}8 \\
\infty \\
\mathbb{1} \\
0\end{array}$ & 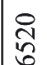 & $\underset{8}{8}$ & $\frac{0}{\sqrt{2}}$ & 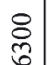 & 无 & $\frac{\infty}{6}$ \\
\hline хәри I & $\begin{array}{l}\circ \\
\frac{0}{0} \\
0 \\
1 \\
1 \\
0\end{array}$ & 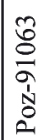 & 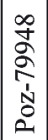 & 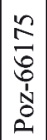 & 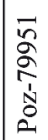 & 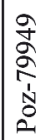 & 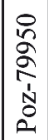 & 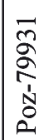 & 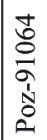 & 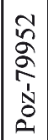 & 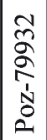 & 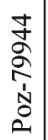 & 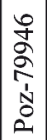 & $\begin{array}{l}1 \\
2 \\
2 \\
2 \\
1 \\
1 \\
0 \\
0\end{array}$ \\
\hline $\begin{array}{r}\text { ə|dures jo } \\
\text { dəquin }_{N}\end{array}$ & 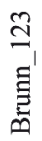 & 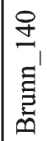 & 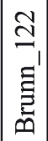 & 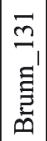 & 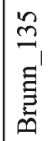 & 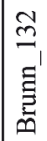 & 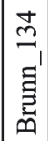 & $\begin{array}{l}m \\
m \\
\vdots \\
\vdots \\
\bar{z}\end{array}$ & $\begin{array}{l}\text { J } \\
\text { 吾 } \\
\text { 总 }\end{array}$ & 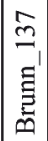 & 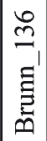 & 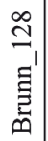 & 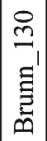 & 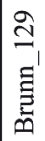 \\
\hline [ห!」ว]вW & 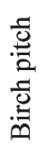 & 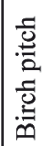 & 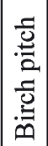 & 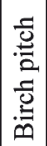 & 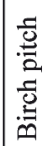 & 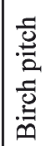 & 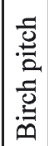 & 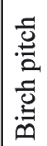 & 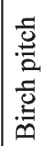 & 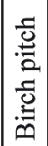 & 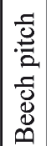 & 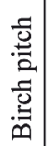 & 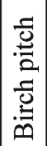 & 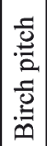 \\
\hline 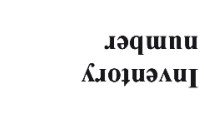 & 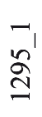 & 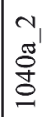 & $\because$ & $\begin{array}{l}m_{1} \\
\stackrel{\Xi}{\Xi} \\
\end{array}$ & $\begin{array}{l}N \\
\tilde{n} \\
\tilde{n} \\
\end{array}$ & 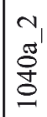 & $\begin{array}{l}N_{1} \\
\stackrel{2}{n} \\
\cong\end{array}$ & $\begin{array}{l}- \\
-\infty \\
\dot{0} \\
\dot{0}\end{array}$ & $=$ & $\begin{array}{l}= \\
\\
8 \\
8 \\
8 \\
\end{array}$ & 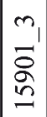 & $\underset{\Xi}{\stackrel{\Xi}{\Xi}}$ & $\begin{array}{l}N_{1} \\
\stackrel{N}{J} \\
\text { I }\end{array}$ & $\begin{array}{l}\tilde{N}_{1} \\
\widetilde{N} \\
\stackrel{\text { I }}{I}\end{array}$ \\
\hline әsnoH & 0 & $a$ & $n$ & $n$ & 음 & $a$ & 음 & $\frac{0}{n}$ & $\underset{n}{\infty}$ & $\infty$ & m & $\infty$ & $\infty$ & $\infty$ \\
\hline ฉวอโด० & 6 & 호 & $\infty$ & $\infty$ & 寻 & 흐 & I & 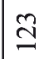 & $\stackrel{m}{\stackrel{2}{I}}$ & $\stackrel{m}{\stackrel{2}{I}}$ & $\underline{2}$ & $\stackrel{5}{2}$ & $\frac{5}{2}$ & $\frac{0}{2}$ \\
\hline 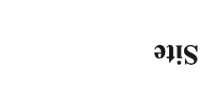 & $\begin{array}{l}\text { N } \\
\text { 音 } \\
\text { 品 }\end{array}$ & 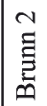 & 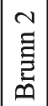 & 吾 & 塄 & 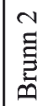 & 罢 & 焉 & 每 & 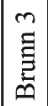 & 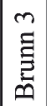 & $\overline{\text { 竞 }}$ & 志 & $\overline{\text { 吾 }}$ \\
\hline วडBपd & - & $\neg$ & - & - & - & - & - & - & $N$ & $N$ & $a$ & m & $m$ & $m$ \\
\hline
\end{tabular}




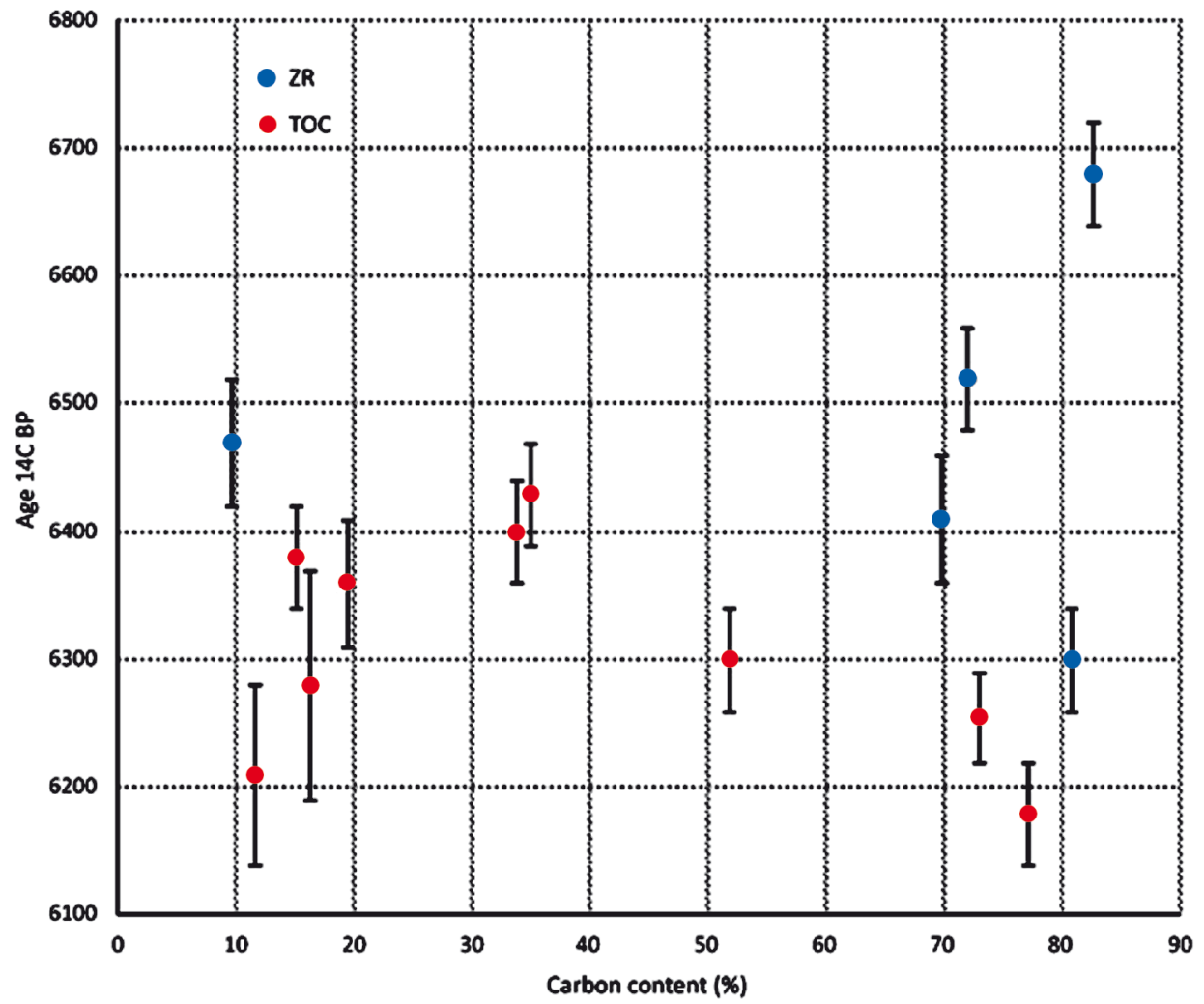

Fig. 7. ${ }^{14} \mathrm{C}$ ages vs percentage of carbon of the bark pitch samples analyzed in the present work. Two methods of sample pretreatment (ZR, TOC - see the text) have been distinguished

We have dated 14 of the samples with bark pitch in the Poznan Radiocarbon Laboratory (Goslar et al. 2004). The other four fragments with this material do not contain enough material for dating. The details of laboratory processing and the dating results are presented in Table 1. Samples of bigger mass, or those appearing to be rich in carbon, were chemically treated with the ZR protocol (after Brock et al. 2010) removing carbonates with $1 \mathrm{M} \mathrm{HCl}$ and humic acids with o.1 $\mathrm{M} \mathrm{NaOH}$. Smaller samples, and samples looking to be poor in carbon, were treated only with $\mathrm{HCl}$, just to avoid complete loss of carbon. In Table 1 , this gentler treatment was coded as TOC (= total organic carbon). Generally the small masses of samples (between 1.5 and 17.3 milligram, see Table 1) generally precluded taking of aliquots for preliminary analysis of carbon content in the raw material, so chemical treatment (either ZR or TOC) was performed on the whole samples available, and carbon content could be determined only after combustion of the material that passed the chemical treatment. So, the preliminary assessment of carbon content (determining the decision 
whether to apply the "strong" (ZR) or the gentle (TOC) treatment) could be checked only after the chemical treatment was completed.

As shown in Table 1 and Fig. 7, carbon percentages in the analyzed samples covered a very wide range (between $9.7 \%$ and $82.6 \%$ ) suggesting that most of these samples were not pure pitch but were rather mixtures of pitch and the ceramic matrix. One could then suppose that old carbon bound to minerals constituting the ceramic matrix, could have affected the dating results. If this were the case, the ${ }^{14} \mathrm{C}$ ages should reveal a negative correlation with the carbon content, a relationship that obviously did not occur (Fig. 7). So, we can claim that the carbon from ceramic matrix, did not affect the dating results in an appreciable way.

On the other hand, ${ }^{14} \mathrm{C}$ ages measured on samples treated with the TOC protocol, on average are 100-150 years younger than the ages of samples that passed the full treatment (ZR). The age difference (of $220 \pm 60{ }^{14} \mathrm{C}$ years) is directly revealed by the two dating results (Poz-91064 and Poz-79952) obtained on samples coming from the same vessel (Inventory number 16040_11), but chemically processed in the two different ways. We thus claim that ${ }^{14} \mathrm{C}$ ages measured on samples treated in the gentler way (TOC) were affected by humic acids, which may be mobile in sediments and might have brought with it carbon descending from later soil horizons. In this respect, ${ }^{14} \mathrm{C}$ ages of samples treated with the ZR protocol may be regarded as the representative ones, whereas those obtained from the TOC fractions should be treated as minimum ages, most probably 100-150 years younger than the actual ages of the analyzed vessels. It is worth pointing out that the range of the " $\mathrm{ZR}$ " ages suggests that the vessels were produced over a rather long period (c. 300 years or more), an indication that seems to be confirmed by the $c$. 250 year span of ${ }^{14} \mathrm{C}$ ages measured on the TOC fractions of the pitch.

\section{CONCLUSION}

The material from the Brunn sites discussed here demonstrate that the Linear Pottery people in 5670-500o BC produced birch and beech bark pitches. They used pottery (big globular vessels and closed high bowls) as containers during the production and for storage of this substance. Two miniature vessels with handle for hanging had contained small portions of birch and beech bark pitches, which could have been used in medicine or as chewing gum. Both possibilities may be assumed for the prehistory (Jensen et al. 2019). We also see evidence of the use of bark pitch as an adhesive for the repair of pottery and in the construction of big idols. An interesting manner of use is the an application of this material in the decoration of ceramics, where we can guess it played a basic role for inlaying items with grains or stones and creation of a contrasting black colour in linear ornamentation. We do not have any material for reconstruction of the use of bark pitch for waterproofing close-shaped vessels as in the Neolithic sites of Northern Greece, which were synchronous with the Brunn sites (Mitkidou et al. 2008). 
Numerous radiocarbon dates for the Brunn sites (Stadler 2019) have shown that bark pitch now is the most reliable material for age determination of Neolithic objects. The significance of this material increases in the study of the micro chronology of the Neolithic and Eneolithic cultures, which existed not more than 600 years, but archaeologists separate two and more periods of their development (as in the Linear Pottery culture). Especially in situations when houses of some periods are located near each other and nobody can be sure about the associations of bones or seeds with any of them.

\section{References}

Brock F., Higham T., Ditchfield P. and Bronk Ramsey C. 2010. Current pretreatment methods for AMS radiocarbon dating at the Oxford Radiocarbon Accelerator Unit (ORAU). Radiocarbon 52, 103-112.

Casanova E., Knowles T. D. J., Bayliss A. et al. 2020. Accurate compound-specific ${ }^{14} \mathrm{C}$ dating of archaeological pottery vessels. Nature 580, 506-510. DOI: 10.1038/s41586-020-2178-z.

Hansen S. 2019. Two Idols from Brunn am Gebirge, Wolfholz. In P. Stadler and N. Kotova, Early Neolithic Settlement Brunn am Gebirge, Wolfholz, Site 2 in Lower Austria and the Origin of the Western Linear Pottery Culture (LPC) (= Beiträge zur Ur- und Frühgeschichte Mitteleuropas 88). Langenweissbach, Wien: Beier \& Beran. Archäologische Fachliteratur, 99-114.

Jensen T. Z. T., Niemann J., Iversen K. H. et al. 2019. A 5700-year-old human genome and oral microbiome from chewed birch pitch. Nature Communications 10, 5520. DOI: 10.1038/s41467019-13549-9.

Gallay G. and Hansen S. 2006. Ein bandkeramischer Statuettenkopf aus Nidderau-Ostheim, MainKinzig-Kreis, Hessen. Germania 84/2, 245-272.

Goslar T., Czernik J. and Goslar E. 2004. Low energy ${ }^{14} \mathrm{C}$ AMS in Poznan Radiocarbon Laboratory, Poland. Nuclear Instruments and Methods in Physics Research Section B 223-224, 5-11.

Kotova N. and Stadler P. 2019. Idols and Clay Objects of Brunn am Gebirge, Wolfholz, Site 2. In P. Stadler and N. Kotova, Early Neolithic Settlement Brunn am Gebirge, Wolfholz, Site 2 in Lower Austria and the Origin of the Western Linear Pottery Culture (LPC) (= Beiträge zur Ur- und Frühgeschichte Mitteleuropas 88). Langenweissbach, Wien: Beier \& Beran. Archäologische Fachliteratur, 377-396.

Kotsakis K., Stratis J. A. and Stephanidou-Stephanatou I. 2008. Organic residue analysis of Neolithic pottery from North Greece. Microchim Acta 160, 493-498.

Kozowyk P.R.B., Soressi M., Pomstra D. et al. 2017. Experimental methods for the Palaeolithic dry distillation of birch bark: implications for the origin and development of Neandertal adhesive technology. Scientific Reports 7, 8033. DOI: 10.1038/s41598-017-08106-7.

Lychagina E. L. and Vybornov A. A. 2017. Chronology of Kama Neolithic culture. Documenta Praehistorica 44, 1 52-161. 
Maniatis Y. and Pappa M. 2020. Radiocarbon Dating of the Neolithic Settlement at Makriyalos, Pieria, North Greece. Radiocarbon 62/2, 467-483.

Mitkidou S., Dimitrakoudi E., Urem-Kotsou D., Papadopoulou D., Kotsakis K., Stratis J. A. and Stephanidou-Stephanatou I. 2008. Organic residue analysis of Neolithic pottery from North Greece. Microchimica Acta 160, 493.

Pesonen P. 1999. Radiocarbon dating of birch bark pitches in typical comb ware in Finland. In M. Huurre (ed.), Dig it All. Papers Dedicated to Ari Sïriäinen. Helsinki: Finnish Antiquarian Society, 191200.

Puchinger L., Sauter F. and Schrattenecker J. D. Chemical Identification of Pitches Found in the Sites of the Early Neolithic Settlement at Brunn am Gebirge, Wolfholz, Studies in Organic Archaeometry IX. In P. Stadler and N. Kotova, Early Neolithic Settlement Brunn am Gebirge, Wolfholz, Site 2 in Lower Austria and the Origin of the Western Linear Pottery Culture (LPC) (= Beiträge zur Ur- und Frühgeschichte Mitteleuropas 88). Langenweissbach, Wien: Beier \& Beran. Archäologische Fachliteratur, 577-582.

Sauter F., Varmuza K., Werther W. and Stadler P. 2019. Chemical Analysis of Organic Material Found in Traces on a Neolithic Terracotta Idol Statuette Excavated in Lower Austria. Studies in Organic Archaeometry V. In P. Stadler and N. Kotova, Early Neolithic Settlement Brunn am Gebirge, Wolfholz, Site 2 in Lower Austria and the Origin of the Western Linear Pottery Culture (LPC) (= Beiträge zur Ur- und Frühgeschichte Mitteleuropas 88). Langenweissbach \& Wien: Beier \& Beran. Archäologische Fachliteratur, 573-576.

Stadler P. 2019. Radiocarbon Dates from the Early Neolithic Site Brunn am Gebirge, Wolfholz. In P. Stadler and N. Kotova, Early Neolithic Settlement Brunn am Gebirge, Wolfholz, Site 2 in Lower Austria and the Origin of the Western Linear Pottery Culture $(L P C)$ (= Beiträge zur Ur- und Frühgeschichte Mitteleuropas 88). Langenweissbach, Wien: Beier \& Beran. Archäologische Fachliteratur, 885-888.

Stadler P. and Kotova N. 2019. Early Neolithic Settlement Brunn am Gebirge, Wolfholz, Site 2 in Lower Austria and the Origin of the Western Linear Pottery Culture (LPC) (= Beiträge zur Urund Frühgeschichte Mitteleuropas 88). Langenweissbach, Wien: Beier \& Beran. Archäologische Fachliteratur.

Tarasov A., Nordqvist K., Mökkönen T. and Khoroshun T. 2017. Radiocarbon chronology of the Neolithic-Eneolithic period in the Karelian Republic (Russia). Documenta Praehistorica 44, 98-121.

Vasilieva I. N. 2006. K voprosu o zarozhdenii goncharsnva v Povolzhie. Voprosy arkheologii Povolzhiya 4, 426-439.

Wiesinger S. 2019. Botanical Remains from the Sites of Brunn am Gebirge, Wolfholz. In P. Stadler and N. Kotova, Early Neolithic Settlement Brunn am Gebirge, Wolfholz, Site 2 in Lower Austria and the Origin of the Western Linear Pottery Culture (LPC) (= Beiträge zur Ur- und Frühgeschichte Mitteleuropas 88). Langenweissbach, Wien: Beier \& Beran. Archäologische Fachliteratur, 517-532. 
